\title{
4-Year Cost Trajectories in Real-World Patients Matched to the Metabolic Profiles of Trial Subjects Before/After Treatment with Phentermine-Topiramate
}

\author{
James $\mathrm{Li}^{1} \cdot$ Nancy L. Reaven ${ }^{2} \cdot$ Susan E. Funk $^{2} \cdot$ Karen McGaughey $^{3}$ • \\ Martin Neovius ${ }^{4}$
}

Published online: 25 April 2015

(c) The Author(s) 2015. This article is published with open access at Springerlink.com

\begin{abstract}
Objective Our objective was to estimate 4-year healthcare costs associated with the metabolic profile of patients before and after 1 year of treatment with phentermine $(15 \mathrm{mg})$ and topiramate extended-release (92 mg) [phentermine-topiramate ER].

Design and Methods Using a medical records database, we created two patient cohorts reflecting metabolic profiles of subjects before and after phentermine-topiramate ER therapy during the 1-year CONQUER trial. We matched database patients with trial subjects by age, sex, body mass index (BMI), and hypertension, glycemic, and triglyceride status. We collected real-world data on emergency department and outpatient visits, hospitalizations, and drug prescriptions over 4 years, linking them to reimbursements to estimate US private insurance costs for post-trial
\end{abstract}

Electronic supplementary material The online version of this article (doi:10.1007/s40801-015-0021-x) contains supplementary material, which is available to authorized users.

Nancy L. Reaven

nancy.reaven@strathealth.com

1 Miles Memorial Hospital, Damariscotta, ME, USA

2 Strategic Health Resources, 4565 Indiana Avenue, La Canada, CA 91011, USA

3 California Polytechnic State University, San Luis Obispo, CA, USA

4 Karolinska Institute, Stockholm, Sweden $(n=2295)$ versus pre-trial intention-to-treat (ITT) patients $(n=2295)$. Secondary analysis assessed responders (completers losing $\geq 5 \%$ body weight $[n=1285]$ ).

Results Over 4 years, the mean cost per patient in the post- versus pre-trial ITT-group was \$US32,432 versus \$US34,725 (mean difference -2292 ; $95 \%$ confidence interval [CI] -4776 to 209). In responders, corresponding costs were \$US30,558 versus \$US33,936 (mean difference -3378; $95 \%$ CI -6496 to -464). Costs for post- versus pretrial responders were lower for outpatient visits, emergency visits, and medications (all $P<0.05$ ).

Conclusion Excluding treatment cost and potential side effects, patients matched to profiles of phentermine-topiramate ER responders had lower costs than patients matched to pre-treatment profiles.

\section{Key Points}

During recent decades, worldwide obesity has increased. The estimated number of obese individuals exceeded 0.5 billion in 2008 ( $7 \%$ of the global population) and currently, $70 \%$ of US adults are either overweight or obese

Obesity is associated with multiple comorbidities, and obese patients incur higher healthcare costs than do non-obese patients

In this study, which matched metabolic profiles before and after drug treatment with those of realworld patients, weight loss of the magnitude achieved in clinical trials with phenterminetopiramate extended-release resulted in lower healthcare costs for responders over 4 years 


\section{Introduction}

Despite public health targets for obesity reduction, the proportion of obese US adults was estimated at $35 \%$ in 2012 [1]. Compared with normal weight individuals, obesity is associated with increased all-cause mortality, primarily due to a strong association with cardiovascular deaths [2-5]. Obesity is also associated with multiple comorbidities, including type 2 diabetes mellitus (T2DM), cardiovascular disease, cancer, asthma, gallbladder disease, osteoarthritis, hyperlipidemia, and chronic back pain [6-9].

Obese individuals have increased comorbidities; therefore, medical costs for these people are significantly higher than those for normal weight individuals $[10,11]$. Furthermore, the cost differential rises as obesity worsens. Two independent observational US database studies reported cost increases of $25 \%$ for class I obese individuals (body mass index [BMI] $30-34.9 \mathrm{~kg} / \mathrm{m}^{2}$ ) and $50 \%$ for class II obese individuals (BMI $35-40 \mathrm{~kg} / \mathrm{m}^{2}$ ) compared with normal weight individuals $[11,12]$. Increases were observed in both inpatient and outpatient categories of service and were also independently observed in costs and numbers of prescriptions $[11,13]$. Data from the US Health and Retirement Study demonstrated a mean increase in medical costs of \$US1829 per year (year 2012 values) for obese compared with normal weight individuals [11].

In 2012, the US FDA approved a combination of phentermine and topiramate extended-release (ER) for chronic weight management with lifestyle modification in patients with obesity-related comorbidities. In intention-totreat (ITT) analysis, this combination led to $\mathrm{a} \geq 10 \%$ weight loss at 1 year in $48 \%$ of patients receiving daily phentermine $(15.0 \mathrm{mg})$ and topiramate ER $(92.0 \mathrm{mg})$ and $37 \%$ of patients receiving daily phentermine $(7.5 \mathrm{mg})$ and topiramate ER $(46.0 \mathrm{mg})$ compared with $7 \%$ in the placebo group [14]. In an extension trial that followed a subgroup of patients who continued the medication, weight loss was sustained at 2 years [15].

Few clinical trials of anti-obesity drugs have included an explicit economic component despite growing concern about the cost of new treatments. In the absence of trial data, most studies of the cost impacts of anti-obesity drugs have employed modeling approaches based on assumptions of weight loss maintenance and a linear relationship between BMI status and costs [16]. A recently published analysis of phentermine-topiramate ER imputed direct medical cost reductions using 1-year patient-reported medication changes during the clinical trial along with assumptions about physician visits, reporting an incremental cost-effectiveness ratio of $\$$ US48,000 per qualityadjusted life-year (QALY) over a 3-year time horizon [17]. We aimed to estimate the change in medical services and costs associated with the metabolic improvements achieved with phentermine-topiramate ER treatment by matching real-world patients to the metabolic profiles of subjects post- and pre-treatment from the CONQUER trial. However, instead of using assumptions about the impact of BMI changes, we used actual patient-level data across a 4-year period.

\section{Methods}

\subsection{Patient Selection}

The primary analysis evaluated patient cohorts modeled on ITT subjects in the phentermine $(15 \mathrm{mg})$ and topiramate ER (92 mg) [phentermine-topiramate ER] study arm of the randomized controlled CONQUER trial [14]. A secondary analysis modeled 'responder' subjects completing the CONQUER trial on phentermine-topiramate ER. Similar to previous work on orlistat and sibutramine [16], 'responders' represented the subgroup of subjects who remained on therapy and lost $\geq 5 \%$ of their body weight by the end of the CONQUER trial.

CONQUER ITT phentermine-topiramate subjects were characterized by sex, age, and inclusion criteria (BMI, glucose status, blood pressure, and triglyceride level) at the beginning (pre-trial) and end (post-trial) of the 1-year CONQUER study. Missing data were handled using last observation carried forward, consistent with the original publication [14].

A set of de-identified Health Insurance Portability and Accountability Act of 1996 (HIPAA)-compliant medical records of patients aged $\geq 40$ years having at least two values for BMI between 2007 and 2011 was obtained from Humedica, Inc. (Cambridge, MA, USA; $n=1.49$ million). Though younger subjects represented $15 \%$ of ITT subjects in the CONQUER study arm we modeled, records for patients under 40 years were not available for release. An index date was assigned to each patient's first encounter that included a valid BMI preceded by $\geq 6$ months of clinical data. For inclusion, patients were required to have $\geq 3$ years of follow-up data from the index date.

Next, CONQUER clinical exclusion criteria were applied to the database patients. Remaining patients were classified by sex, age, BMI, hypertension status, glycemic status, and triglyceride status on their index dates. To develop patient cohorts, up to three patients from the remaining pool of eligible database patients were matched (with replacement) to each CONQUER subject's post-trial and pre-trial states using the following six criteria: age ( \pm 3 years), sex, BMI $\left( \pm 1 \mathrm{~kg} / \mathrm{m}^{2}\right)$, hypertension status, glycemic status (normal, prediabetes, or diabetes), and 
hypertriglyceridemia status (for further details, see the Electronic Supplementary Material [ESM] 1, Figure S1).

Hypertension was defined as diastolic blood pressure $\geq 90 \mathrm{mmHg}(\geq 85 \mathrm{mmHg}$ with T2DM), systolic blood pressure $\geq 140 \mathrm{mmHg}$ ( $\geq 130 \mathrm{mmHg}$ with $\mathrm{T} 2 \mathrm{DM})$, use of any anti-hypertensive medication, or a diagnosis code indicating hypertension. T2DM was defined as glycosylated hemoglobin $\left(\mathrm{HbA}_{1 \mathrm{c}}\right) \geq 6.5 \%$, fasting glucose $\geq 126$ $\mathrm{mg} / \mathrm{dL}$, use of any anti-diabetic medication, or a diagnosis code indicating T2DM. Prediabetes (in patients without T2DM) was defined as $\mathrm{HbA}_{1 \mathrm{c}}$ 5.7-6.4\%, fasting glucose $100-125 \mathrm{mg} / \mathrm{dL}$, or a diagnosis code indicating prediabetes. Hypertriglyceridemia was defined as $\geq 200 \mathrm{mg} /$ $\mathrm{dL}$ or two or more lipid-lowering medications.

\subsection{Utilization and Costs}

For each database patient included in the matched study population, tabulations were made of inpatient, outpatient, and emergency department visits; lab tests; and written prescriptions for up to 4 years following the patient's index date. Outpatient visits were defined as encounters that included a physical observation, diagnosis code, or a procedure other than specimen collection or lab testing on a day that did not include inpatient or emergency department care. We counted all outpatient care received by a patient on 1 day as a single outpatient visit.

Written prescriptions were categorized by generic name without regard to dose. That is, all doses of a specific medication were considered to be the same medication. Combination pharmaceuticals were classified according to major or first-listed ingredient, with the exception of acetaminophen/codeine and acetaminophen/oxycodone. When the number of refills was not specified, we used the mean number of refills for the specific medication calculated from the overall dataset. For medications without mean refill data, we used the mean number of refills of that medication's class or, in rare instances, the mean number of refills of all medications in the dataset.

To assess US private insurer costs, data from OptumInsight (Minneapolis, MN, USA) were obtained on calendar year 2011 private insurance plan costs for inpatient stays by diagnosis-related group (DRG), outpatient visits by type, and emergency department visits, along with 139 of the most common prescription drugs (representing $75 \%$ of all prescriptions in the study period) and the 34 most common laboratory tests (representing $73 \%$ of all tests). Cost is presented from a private insurance plan perspective. Throughout, the terms 'cost' and 'costs' refer to insuranceallowed reimbursements, defined as the amount payable after discounts but prior to application of any deductible, copay, co-insurance, or coordination of benefits.
Cost for each hospital inpatient stay was estimated using length of stay, DRG-specific cost per day, and the mean physician cost per inpatient day (details in ESM 1). For encounters or services that were identified in the data but could not be classified (e.g., an inpatient stay with no diagnosis code or a prescription with no medication name), we applied the weighted mean cost of that type of service from the overall dataset. Though the costs of laboratory tests were included in outpatient encounter costs, outpatient laboratory utilization was assessed separately from other outpatient encounters to avoid skewing utilization totals.

\subsection{Follow-Up}

Healthcare utilization and costs were evaluated in patients matched to the CONQUER pre-trial and post-trial subjects for up to 4 years after a patient's index date, with no requirement with respect to weight maintenance, loss, or gain or any other metabolic changes. At the time of this analysis, long-term patient adherence, treatment efficacy, and safety of phentermine-topiramate are not known. Accordingly, our methodology did not exclude patients who gained weight during the 4 years of followup, nor did we attempt to adjust the outcomes to account for the possibility of weight rebound or further weight loss.

The non-discounted cost of phentermine-topiramate ER treatment, currently \$US2868 per year [18, 19], was not incorporated into the analysis.

\subsection{Statistical Methods}

$P$ values and $95 \%$ confidence intervals (CIs) for the differences in means were calculated using non-parametric bootstrapping to avoid distributional assumptions. Analyses were carried out with SAS version 9.2.

\section{Results}

\subsection{Patient Characteristics}

Mean BMI was $32 \mathrm{~kg} / \mathrm{m}^{2}$ among patients matched to the post-trial state of CONQUER ITT subjects compared with a mean BMI of $36 \mathrm{~kg} / \mathrm{m}^{2}$ among patients matched to the pre-trial state of such subjects. Among responders, constituting $56 \%$ of the sample (1289/2295), the mean BMI comparison between post- versus pre-trial groups was 31 versus $36 \mathrm{~kg} / \mathrm{m}^{2}$. Demographic characteristics of the patients matched to CONQUER subjects are listed in Table 1. 
Table 1 Baseline characteristics of study population(s)

\begin{tabular}{|c|c|c|c|c|c|c|}
\hline \multirow[b]{2}{*}{ Model set } & \multicolumn{2}{|c|}{$\begin{array}{l}\text { Primary comparison } \\
\text { (matched to ITT) }\end{array}$} & \multicolumn{4}{|c|}{$\begin{array}{l}\text { Secondary comparison } \\
\text { (matched to responders) }\end{array}$} \\
\hline & Pre-trial & Post-trial & $P$ value & Pre-trial & Post-trial & $P$ value \\
\hline $\mathrm{N}$ & 2295 & 2295 & & 1289 & 1289 & \\
\hline Mean age in years (SD) & $54(8)$ & $55(8)$ & & $54(8)$ & $55(8)$ & \\
\hline Women, n (\%) & $1613(70)$ & $1613(70)$ & & $905(70)$ & $905(70)$ & \\
\hline BMI $\left(k g / m^{b}\right)$, mean (SD) & $36(4)$ & $32(5)$ & $<.0001$ & $36(4)$ & $31(4)$ & $<.0001$ \\
\hline \multirow[t]{2}{*}{ Type 2 diabetes ${ }^{a}, \mathrm{n}(\%)$} & $475(21)$ & 428 (19) & & $229(18)$ & $155(12)$ & \\
\hline & & & 0.17 & & & $<.0001$ \\
\hline Prediabetes $^{\mathrm{b}}, \mathrm{n}(\%)$ & $1182(52)$ & $1192(52)$ & & $711(55)$ & $708(55)$ & \\
\hline Hypertension $^{c}$, n (\%) & $1786(78)$ & $1620(71)$ & $<.0001$ & $1023(79)$ & $888(69)$ & $<.0001$ \\
\hline $\begin{array}{l}\text { Elevated triglycerides }{ }^{d}, \mathrm{n} \\
(\%)\end{array}$ & $571(25)$ & $289(13)$ & $<.0001$ & $349(27)$ & $139(11)$ & $<.0001$ \\
\hline
\end{tabular}

Data are presented as $n(\%)$ unless otherwise indicated

$B M I$ body mass index, $H b A_{l c}$ glycosylated hemoglobin, $I T T$ intent-to-treat population, $S D$ standard deviation, $T 2 D M$ type 2 diabetes mellitus a $\mathrm{T} 2 \mathrm{DM}$ (any criterion): $\mathrm{HbA}_{1 \mathrm{c}} \geq 6.5 \%$; fasting glucose $\geq 126 \mathrm{mg} / \mathrm{dL}$; any anti-diabetes medication; diagnosis codes indicating T2DM

b Prediabetes (in patients without diabetes, any criterion): $\mathrm{HbA}_{1 \mathrm{c}} 5.7 \%-6.4 \%$; fasting glucose $100-125 \mathrm{mg} / \mathrm{dL}$; diagnoses codes indicating prediabetes

c Hypertension (any criterion): diastolic blood pressure $\geq 90$ ( $\geq 85$ with T2DM); systolic blood pressure $\geq 140$ ( $\geq 130$ with T2DM); any antihypertensive medication; diagnosis codes indicating hypertension

d Hypertriglyceridemia: $\geq 200 \mathrm{mg} / \mathrm{dL}$ or more than one lipid-lowering drug

\subsection{Health Resources Utilization}

\subsubsection{Primary Analysis}

Patients matched to post-trial CONQUER ITT subjects sought fewer services during the 4-year study period than did patients matched to pre-trial CONQUER ITT subjects (Fig. 1). Patients matched to post-trial CONQUER ITT subjects (Fig. 1a) had fewer outpatient visits (39 vs. 42; mean difference $-3 ; 95 \% \mathrm{CI}-5$ to $-2 ; P<0.001)$ and received fewer prescriptions (40 vs. 45 ; mean difference $-5 ; 95 \% \mathrm{CI}-7$ to $-3 ; P<0.001)$ than patients matched to pre-trial CONQUER ITT subjects. No differences were observed between the post- and pre-trial matching groups for inpatient admissions ( 0.43 vs. 0.46 ; mean difference $-0.03 ; 95 \%$ CI -0.10 to $0.04 ; P=0.44$ ) or emergency department visits ( 0.9 vs. 1.0 ; mean difference $-0.1 ; 95 \%$ CI -0.30 to $-0.02 ; P=0.08)$.

\subsubsection{Secondary Analysis (Responders)}

Patients matched to post-trial responder subjects (Fig. 1b) had fewer outpatient visits (37 vs. 41 ; mean difference -4 ;
$95 \%$ CI -2 to $-6 ; P<0.001$ ), fewer prescriptions ( 37 vs. 45 ; mean difference $-8 ; 95 \% \mathrm{CI}-11$ to $-6 ; P<0.001)$, and fewer emergency department visits ( 0.8 vs. 1.1 ; mean difference $-0.3 ; 95 \% \mathrm{CI}-0.5$ to $-0.1 ; P<0.01)$ than patients matched to pre-trial responder subjects. No difference was observed for inpatient admissions ( 0.40 vs. 0.45 ; mean difference $-0.05 ; 95 \% \mathrm{CI}-0.15$ to $0.04 ; P=0.26$ ).

\subsection{Healthcare Costs}

\subsubsection{Primary Analysis}

Over 4 years, mean per-patient costs for patients matched to post- versus pre-trial CONQUER ITT subjects were \$US32,432 and \$US34,725 (mean difference -2292; $95 \%$ CI -4776 to $209 ; P=0.08$ ). While this overall difference did not reach statistical significance, patients matched to post- versus pre-trial CONQUER subjects had significantly lower outpatient costs (\$US16,901 vs. $\$$ US18,035; mean difference $-1134,95 \% \mathrm{CI}-2122$ to $-110 ; P=0.03$ ) and lower total prescription costs (\$US7271 vs. \$US8331; mean difference $-1060 ; 95 \%$ CI -1553 to -558 ; $P<0.001$; Fig. 2). Lower prescription costs were reflected 
a Utilization: Intent-to-Treat

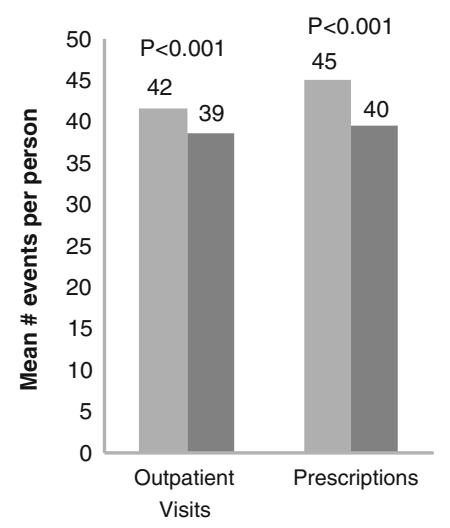

b Utilization: Responder

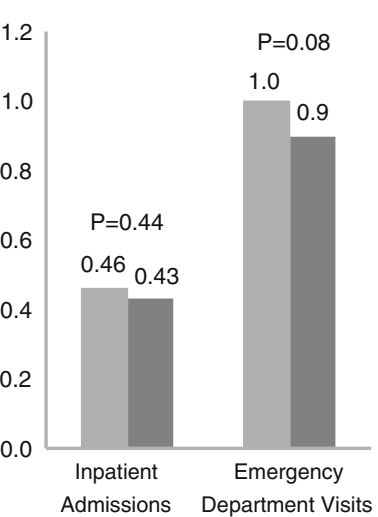

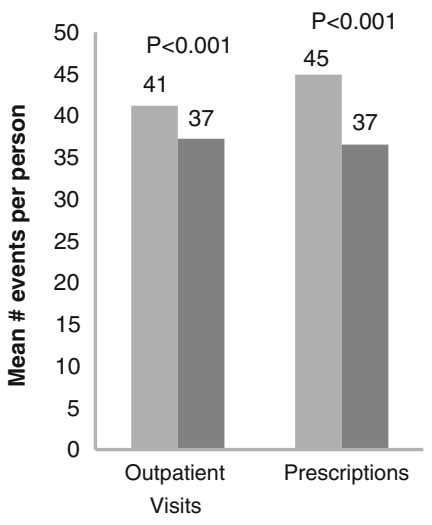

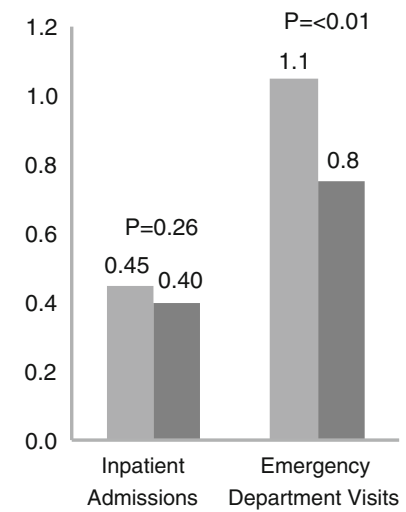

Patients matching pre-trial subjects

Patients matching post-trial subjects

Fig. 1 Mean per-patient utilization of outpatient visits, inpatient admissions, and emergency department visits, and mean number of prescriptions written during study period. $P$ values estimated using nonparametric bootstrapping. ITT intention-to-treat
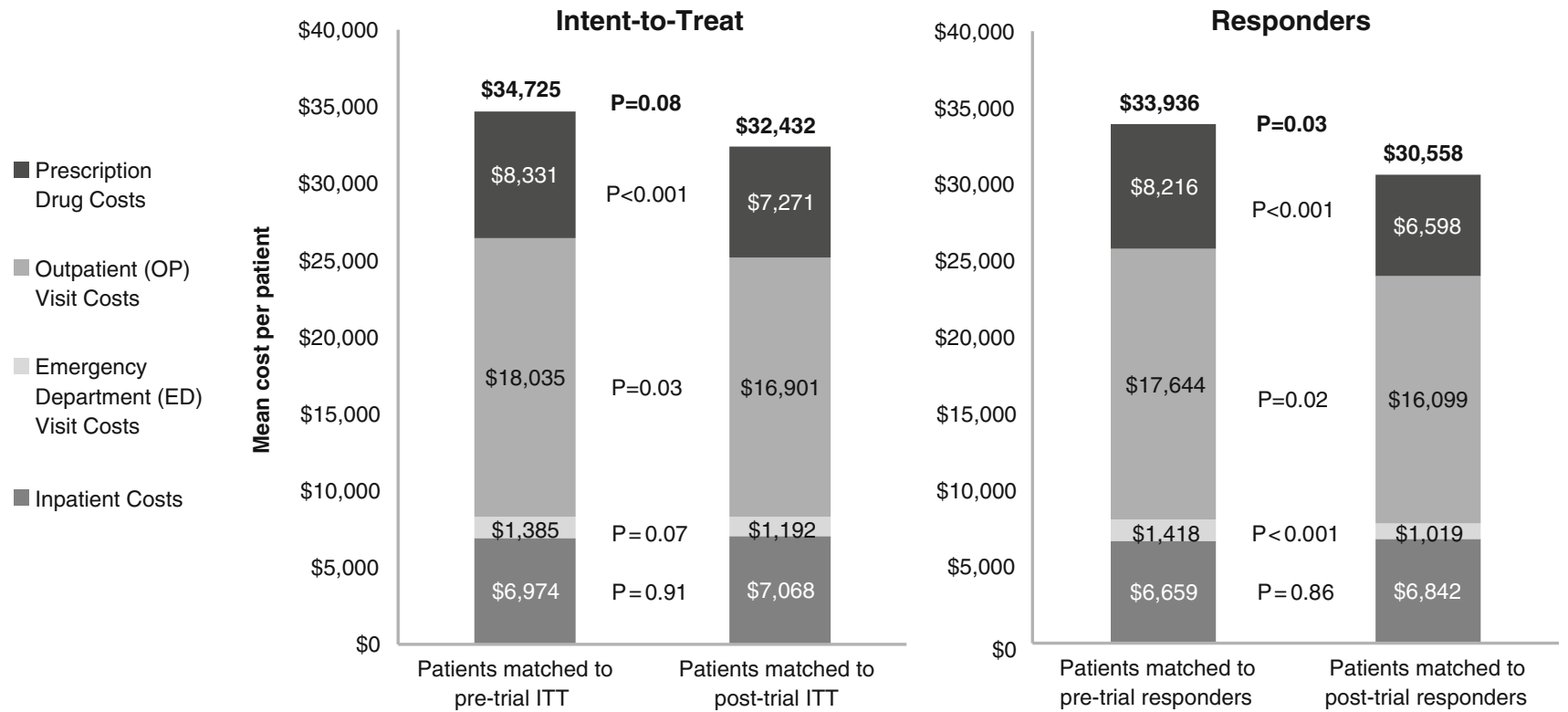

Fig. 2 Mean healthcare cost per patient during 4-year study period, by category of service. $P$ values estimated using nonparametric bootstrapping. ITT intention-to-treat

in all medication groups as well as specifically in three categories of medications commonly used to treat obesityrelated comorbidities (Fig. 3).

No differences between the post- and pre-trial groups were observed in inpatient costs (\$US7068 vs. \$US6974; mean difference $95 ; 95 \% \mathrm{CI}-1632$ to $1895 ; P=0.91)$ or emergency department costs (\$US1192 vs. \$US1385; mean difference $-193 ; 95 \% \mathrm{CI}-405$ to $2 ; P=0.07$ ).

\subsubsection{Secondary Analysis (Responders)}

In the secondary analysis of responders, mean costs in patients matched to post- versus pre-trial subjects were \$US30,558 and \$US33,936 (mean difference -3378; $95 \%$ CI -6496 to $-464 ; P=0.03$ ). In subgroup analysis, patients matched to post- versus pre-trial subjects had significantly lower outpatient costs (\$US16,099 vs. 


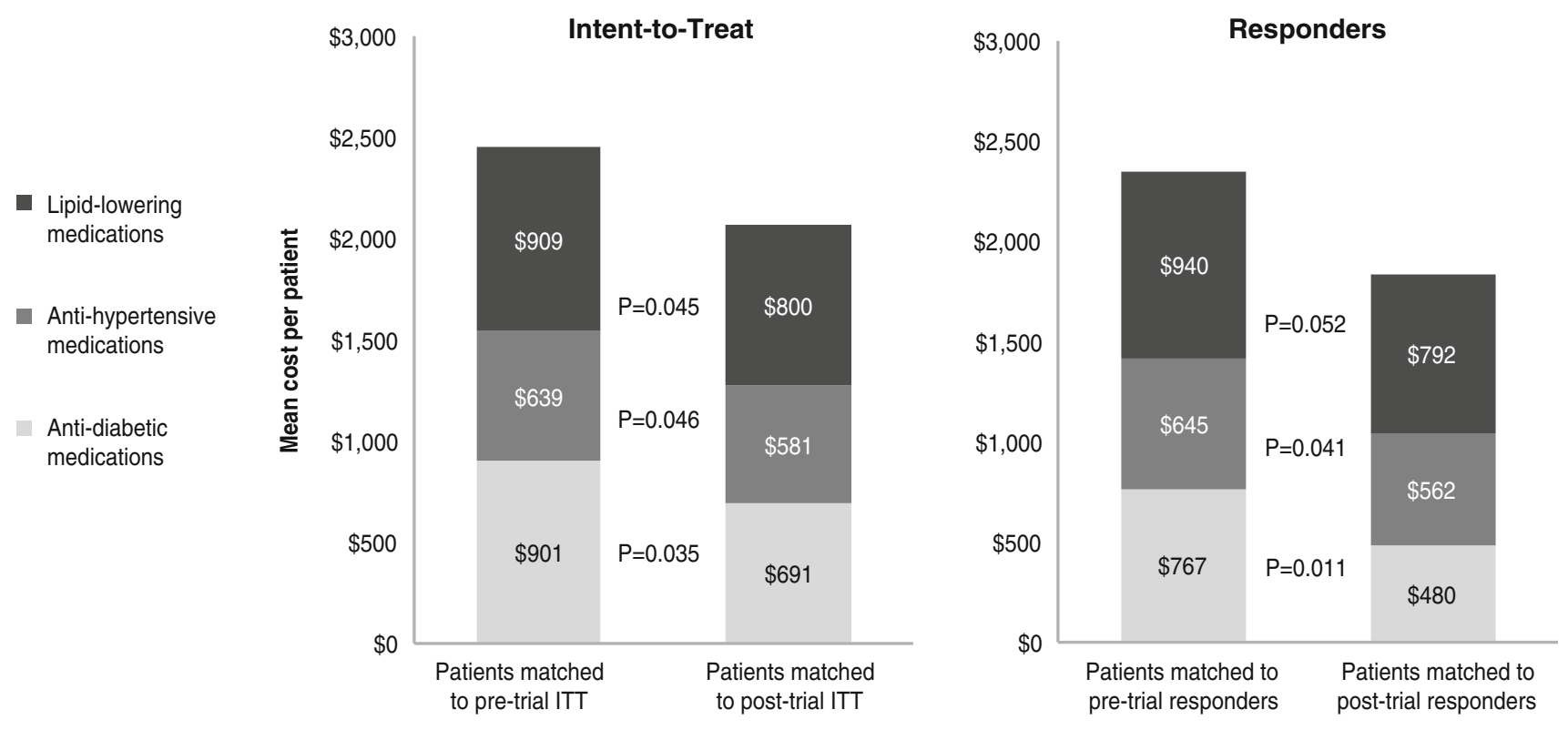

Fig. 3 Mean cost of prescriptions for diabetes, hypertension, and elevated lipids during 4-year study period. $P$ values estimated using nonparametric bootstrapping. ITT intention-to-treat

\$US17,644; mean difference $-1545 ; 95 \%$ CI -2800 to $-208 ; P=0.02$ ), lower prescription costs (\$US6598 vs. \$US8216; mean difference -1618 ; $95 \%$ CI -2216 to $-1002 ; P<0.001)$, and lower emergency department costs (\$US1019 vs. \$US1418; mean difference -399; $95 \%$ CI -639 to $-143 ; P<0.001)$. No difference between the postand pre-trial responder groups was observed in inpatient costs (\$US6842 vs. \$US6659; mean difference 184; $95 \%$ CI -1986 to 2096; $P=0.86)$.

\section{Discussion}

\subsection{Main Findings}

We studied healthcare cost trajectories over 4 years in patient groups with metabolic profiles reflecting the posttrial and pre-trial characteristics of patients receiving 12 months of phentermine-topiramate ER treatment. Excluding phentermine-topiramate ER costs, we found no statistically significant difference in costs overall among the ITT-matched group, but did observe cost savings for responders (patients matched to study completers losing $\geq 5 \%$ of initial weight). The bulk of estimated savings (94\%) originated from lower prescription medication costs as well as emergency department and outpatient visit costs.

\subsection{Previous Research}

Several cost-effectiveness analyses have been published for the anti-obesity drugs orlistat, sibutramine, and rimonabant [16]. These analyses have generally modeled costs over the long term based on assumptions regarding weight loss maintenance and a linear relationship between BMI status and costs. When the weight loss drug cost was included, none of these modeling studies found drug treatment to be cost saving compared with standard care. Nevertheless, most found the drugs to be within the boundaries of what is generally regarded as cost effective. The majority of the studies used a treatmentresponder approach, where patients not losing $>5 \%$ of initial weight after 3 months were taken off drug. A recent study modeled the cost effectiveness of Qsymia versus diet and lifestyle using 1-year self-reported healthcare utilization and quality-of-life data and assumptions regarding maintenance of effects over an additional 2 years [17]. The study found Qsymia to be associated with an incremental cost-effectiveness ratio of \$US48,000 per QALY, but that the result was sensitive to assumptions regarding extrapolation of effects beyond the first year. The study did not investigate cost effectiveness according to the treatment-responder approach recommended for clinical use of the drug.

Our cost analysis entailed a design that identified actual patients in a US database matched to pre- and post-trial patient characteristics. Excluding intervention costs, we analyzed costs for all patients as well as for the subset of treatment responders defined as $\geq 5 \%$ weight loss at 12 months. Our design does not allow direct comparisons with the modeled costs in previous cost-effectiveness analyses. However, given that the 12-month placebo-adjusted weight loss for phentermine-topiramate ER was approximately $9 \mathrm{~kg}$ (compared with $<5 \mathrm{~kg}$ for sibutramine and rimonabant and $<3 \mathrm{~kg}$ for orlistat) [14, 20], one would expect greater health improvements and cost effects with phentermine-topiramate ER. 


\subsection{Mechanisms}

Voluntary weight loss and accompanying improvements in metabolic risk factors may result in lower drug use and reduced healthcare needs through several mechanisms, including better glycemic control and prevention of cardiovascular events. Bariatric surgery, which results in substantial and sustained weight loss, has been shown both to prevent T2DM in non-diabetic patients [21] and to induce remission of disease [22, 23]. Also, lower incidences of stroke and myocardial infarction have been reported [24]. However, over up to 20 years of follow-up, healthcare use was similar or higher in the surgery group than in the control group in the Swedish Obese Subjects study, while prescription costs were lower [25].

Drug-induced weight loss is of lower magnitude than surgery-induced weight loss and has not been shown to be as sustainable [20, 26]. Still, randomized placebo-controlled trials of both orlistat and phentermine-topiramate ER have shown lower incidence of T2DM over 4 and 2 years, respectively $[27,28]$. This is likely to translate into lower costs for medication and clinical follow-up of diabetes. In our analysis over 4 years, we found lower costs for anti-diabetes drugs in the post- vs. pre-trial ITT group $(P=0.04)$.

Regarding cardiovascular events, no data exist for orlistat or phentermine-topiramate ER, although both drugs have beneficial short-term effects on intermediate measures such as lipids and blood pressure [14, 20]. In the only completed randomized trial to date of a weight-loss drug with cardiovascular events as primary outcome, a small but statistically significantly higher risk was observed in sibutramine-treated patients than in those receiving placebo, leading to withdrawal of market authorization [29]. Rimonabant was also tested for prevention of cardiovascular events in a study enrolling more than 18,000 patients, but the trial was terminated prematurely due to neuropsychiatric effects [30].

In contrast to both orlistat and phentermine-topiramate ER, sibutramine has been shown to be associated with increases in blood pressure compared with placebo [14, 31]. However, like sibutramine, phentermine-topiramate ER has been reported to raise heart rate, although the clinical importance of this finding is currently unclear [32]. Concerns about potential adverse events, including cardiovascular events, resulted in the European Medicines Agency (EMA) rejecting the market application for phentermine-topiramate ER [33]. Long-term cardiovascular outcomes of phentermine-topiramate ER are being investigated in the AQCLAIM (A Qsymia Cardiovascular morbidity and Mortality) study, in accordance with post-marketing requirements of the FDA (ClinicalTrials.gov; EudraCT Number 2012-003946-34).

\subsection{Strengths}

Our cost analysis used a different approach to estimate costs over 4 years than prior cost-effectiveness analyses of weight-loss drugs [16]. Instead of assuming a linear relationship between BMI, body weight, or weight loss on the one hand and costs on the other, we matched real-world patients to six metabolic and demographic parameters of CONQUER trial patients before and after phenterminetopiramate ER treatment and observed actual medical service utilization and costs over 4 years. These cost estimates, based on observed resource use between 2007 and 2011 and average per-service costs for insured US patients in 2011, are likely more generalizable to the US setting than estimates from hypothetical cohorts of patients and modeled costs generated by other cost-effectiveness models.

\subsection{Limitations}

This study is an examination of resource use and related costs in patients with characteristics mirroring the characteristics of patients before and after 12 months of phentermine-topiramate ER treatment. Since 4-year follow-up data on patients taking phentermine-topiramate ER are unavailable, we were unable to assess the extent to which changes in weight and metabolic markers in the patients whose natural history we followed could differ from results in actual phentermine-topiramate ER patients over a similar period. Therefore, the results need to be validated, preferably in both observational and randomized intervention studies.

As we did not observe actual phentermine-topiramate ER-treated patients, we also did not include costs for potential short- or long-term adverse events. Both sibutramine (USA and Europe) and rimonabant (Europe) were withdrawn from the market because of their adverse event profile after initially being approved. The safety of phentermine-topiramate ER beyond 2 years is currently unknown [15]. We also did not include phenterminetopiramate ER drug costs, which would require us to make assumptions regarding duration of treatment, compliance, and weight development over the 4 years of follow-up.

The patient groups we created did not fully reflect patients in the CONQUER trial. Specifically, we only had access to patients aged $\geq 40$ years, representing $85 \%$ of CONQUER ITT subjects in the modeled study arm; we did not match on race or smoking history because a large number of database records lacked these; we did not have information on mortality or direct information on when patients may have transferred their care to another provider system; and we did not have a full 4 years of follow-up data for all patients. However, these limitations applied to both the pre- and the post-trial patient groups. 


\section{Conclusion}

In this database study, which explored the potential 4-year cost effects of metabolic improvements observed over 12 months of phentermine-topiramate ER treatment, we detected some health resource utilization differences, but no statistically significant overall cost differences between patients representing post- versus pre-trial metabolic profiles in the ITT analysis. When restricting our analysis to patients losing $\geq 5 \%$ of initial body weight, the threshold used in some countries for continuing weight-loss drug treatment and the threshold used by the manufacturer in its instructions to patients [16, 32], cost savings of about \$US3400 were observed over 4 years, reflecting reduced utilization of all measured categories of medical services except inpatient admissions. Future analyses should factor in costs related to treatment of adverse events and compliance-based costs of the treatment itself. We recommend validation of these findings in observational and randomized intervention studies.

Acknowledgments All authors were involved in all aspects of the study design, data collection, analysis, interpretation and writing of this manuscript.

Conflict of interest This study was funded by Vivus, Inc. However, the trial was designed, conducted, analyzed, interpreted, and written by investigators independent of Vivus.

Open Access This article is distributed under the terms of the Creative Commons Attribution-NonCommercial 4.0 International License (http://creativecommons.org/licenses/by-nc/4.0/), which permits any noncommercial use, distribution, and reproduction in any medium, provided you give appropriate credit to the original author(s) and the source, provide a link to the Creative Commons license, and indicate if changes were made.

\section{References}

1. Ogden CL, Carroll MD, Kit BK, Flegal KM. Prevalence of childhood and adult obesity in the United States, 2011-2012. JAMA. 2014;311(8):806-14.

2. Flegal KM, Graubard BI, Williamson DF, Gail MH. Causespecific excess deaths associated with underweight, overweight, and obesity. JAMA. 2007;298(17):2028-37.

3. McGee DL. Body mass index and mortality: a meta-analysis based on person-level data from twenty-six observational studies. Ann Epidemiol. 2005;15(2):87-97.

4. Whitlock G, Lewington S, Sherliker P, Clarke R, Emberson J, Halsey $\mathrm{J}$, et al. Body-mass index and cause-specific mortality in 900,000 adults: collaborative analyses of 57 prospective studies. Lancet. 2009;373(9669):1083-96.

5. Berrington de Gonzalez A, Hartge P, Cerhan JR, Flint AJ, Hannan L, MacInnis RJ, et al. Body-mass index and mortality among 1.46 million white adults. N Engl J Med. 2010;363(23):2211-9.

6. Must A, Spadano J, Coakley EH, Field AE, Colditz G, Dietz WH. The disease burden associated with overweight and obesity. JAMA. 1999;282(16):1523-9.
7. Field AE, Coakley EH, Must A, Spadano JL, Laird N, Dietz WH, et al. Impact of overweight on the risk of developing common chronic diseases during a 10-year period. Arch Intern Med. 2001;161(13):1581-6.

8. Renehan AG, Tyson M, Egger M, Heller RF, Zwahlen M. Bodymass index and incidence of cancer: a systematic review and meta-analysis of prospective observational studies. Lancet. 2008;371(9612):569-78.

9. Guh DP, Zhang W, Bansback N, Amarsi Z, Birmingham CL, Anis $\mathrm{AH}$. The incidence of co-morbidities related to obesity and overweight: a systematic review and meta-analysis. BMC Public Health. 2009;9:88

10. Padula WV, Allen RR, Nair KV. Determining the cost of obesity and its common comorbidities from a commercial claims database. Clin Obes. 2014;4(1):53-8.

11. Andreyeva T, Sturm R, Ringel JS. Moderate and severe obesity have large differences in health care costs. Obes Res. 2004;12(12):1936-43.

12. Quesenberry CP Jr, Caan B, Jacobson A. Obesity, health services use, and health care costs among members of a health maintenance organization. Arch Intern Med. 1998;158(5):466-72.

13. Narbro K, Ågren G, Jonsson E, Näslund I, Sjöström L, Peltonen M. Pharmaceutical costs in obese individuals: comparison with a randomly selected population sample and long-term changes after conventional and surgical treatment: the SOS intervention study. Arch Intern Med. 2002;162(18):2061-9.

14. Gadde KM, Allison DB, Ryan DH, Peterson CA, Troupin B, Schwiers ML, et al. Effects of low-dose, controlled-release, phentermine plus topiramate combination on weight and associated comorbidities in overweight and obese adults (CONQUER): a randomised, placebo-controlled, phase 3 trial. Lancet. 2011;377(9774):1341-52.

15. Garvey WT, Ryan DH, Look M, Gadde KM, Allison DB, Peterson $\mathrm{CA}$, et al. Two-year sustained weight loss and metabolic benefits with controlled-release phentermine/topiramate in obese and overweight adults (SEQUEL): a randomized, placebo-controlled, phase 3 extension study. Am J Clin Nutr. 2012;95(2):297-308.

16. Neovius M, Narbro K. Cost-effectiveness of pharmacological anti-obesity treatments: a systematic review. Int J Obes (Lond). 2008;32(12):1752-63.

17. Finkelstein EA, Kruger E, Karnawat S. Cost-effectiveness analysis of Qsymia for weight loss. PharmacoEconomics. 2014. doi:10.1007/s40273-014-0182-6.

18. CVS Pharmacy. 2014. http://www.cvs.com/drug/qsymia/oralcapsule-extended-release/15-92mg. Accessed 14 Apr 2014.

19. Hannaford. 2014 [cited 2015 March 13]; Available from: http:// www.hannaford.com/content.jsp?pageName=HSPDrugPrice\&left NavArea=PharmacyLeftNav.

20. Rucker D, Padwal R, Li SK, Curioni C, Lau DC. Long term pharmacotherapy for obesity and overweight: updated metaanalysis. BMJ. 2007;335(7631):1194-9.

21. Carlsson LM, Peltonen M, Ahlin S, Anveden A, Bouchard C, Carlsson B, et al. Bariatric surgery and prevention of type 2 diabetes in Swedish obese subjects. $N$ Engl J Med. 2012;367(8):695-704.

22. Sjostrom L, Lindroos AK, Peltonen M, Torgerson J, Bouchard C, Carlsson $\mathrm{B}$, et al. Lifestyle, diabetes, and cardiovascular risk factors 10 years after bariatric surgery. $N$ Engl $\mathrm{J}$ Med. 2004;351(26):2683-93.

23. Sjostrom L, Peltonen M, Jacobson P, Ahlin S, Andersson-Assarsson J, Anveden A, et al. Association of bariatric surgery with long-term remission of type 2 diabetes and with microvascular and macrovascular complications. JAMA. 2014;311(22):2297-304.

24. Sjostrom L, Peltonen M, Jacobson P, Sjostrom CD, Karason K, Wedel $\mathrm{H}$, et al. Bariatric surgery and long-term cardiovascular events. JAMA. 2012;307(1):56-65. 
25. Neovius M, Narbro K, Keating C, Peltonen M, Sjoholm K, Agren $\mathrm{G}$, et al. Health care use during 20 years following bariatric surgery. JAMA. 2012;308(11):1132-41.

26. Buchwald H, Avidor Y, Braunwald E, Jensen MD, Pories W, Fahrbach K, et al. Bariatric surgery: a systematic review and meta-analysis. JAMA. 2004;292(14):1724-37.

27. Torgerson JS, Hauptman J, Boldrin MN, Sjostrom L. XENical in the prevention of diabetes in obese subjects (XENDOS) study: a randomized study of orlistat as an adjunct to lifestyle changes for the prevention of type 2 diabetes in obese patients. Diabetes Care. 2004;27(1):155-61.

28. Garvey WT, Ryan DH, Henry R, Bohannon NJ, Toplak H, Schwiers M, et al. Prevention of type 2 diabetes in subjects with prediabetes and metabolic syndrome treated with phentermine and topiramate extended-release. Diabetes Care. 2014;37(4):912-21.

29. James WP, Caterson ID, Coutinho W, Finer N, Van Gaal LF, Maggioni AP, et al. Effect of sibutramine on cardiovascular outcomes in overweight and obese subjects. N Engl J Med. 2010;363(10):905-17.

30. Topol EJ, Bousser MG, Fox KA, Creager MA, Despres JP, Easton JD, et al. Rimonabant for prevention of cardiovascular events (CRESCENDO): a randomised, multicentre, placebocontrolled trial. Lancet. 2010;376(9740):517-23.

31. Johansson K, Sundstrom J, Neovius K, Rossner S, Neovius M. Long-term changes in blood pressure following orlistat and sibutramine treatment: a meta-analysis. Obes Rev. 2010;11(11):777-91.

32. Woloshin S, Schwartz LM. The new weight-loss drugs, lorcaserin and phentermine-topiramate: slim pickings? JAMA Intern Med. 2014;174(4):615-9.

33. European Medicines Agency. Refusal of the marketing authorisation for Qsiva (phentermine / topiramate). EMA; 2012. Available from: http://www.ema.europa.eu/docs/en_GB/document_library/ Summary_of_opinion_-_Initial_authorisation/human/002350/WC5 00134085.pdf. 2014 [cited 2015 March 13]. 